\title{
GMP-Compliant Human Fetal Skin Fibroblasts for Wound Healing
}

\author{
Parisa Goodarzi, ${ }^{1}$ Khadijeh Falahzadeh, ${ }^{2}$ Hamidreza Aghayan, ${ }^{3}$ Fereshteh Mohamadi Jahani, ${ }^{1}$ Moloud \\ Payab, ${ }^{4}$ Kambiz Gilany, ${ }^{2,5}$ Fakher Rahim, ${ }^{6}$ Bagher Larijani, ${ }^{7}$ Akram Tayanloo Beik, ${ }^{3}$ Hossein Adibi, ${ }^{8}$ and \\ Babak Arjmand ${ }^{2,3,{ }^{*}}$ \\ ${ }^{1}$ Brain and Spinal Cord Injury Research Center, Neuroscience Institute, Tehran University of Medical Sciences, Tehran, IR Iran \\ ${ }^{2}$ Metabolomics and Genomics Research Center, Endocrinology and Metabolism Molecular-Cellular Sciences Institute, Tehran University of Medical Sciences, Tehran, IR Iran \\ ${ }^{3}$ Cell Therapy and Regenerative Medicine Research Center, Endocrinology and Metabolism Molecular-Cellular Sciences Institute, Tehran University of Medical Sciences, \\ Tehran, IR Iran \\ ${ }^{4}$ Obesity and Eating Habits Research Center, Endocrinology and Metabolism Molecular-Cellular Sciences Institute, Tehran University of Medical Sciences, Tehran, IR Iran \\ ${ }^{5}$ Reproductive Biotechnology Research Center, Avicenna Research Institute, ACECR, Tehran, IR Iran \\ ${ }^{6}$ Health Research Institute, Thalassemia and Hemoglobinopathy Research Center, Ahvaz Jundishapur University of Medical Sciences, Ahvaz, IR Iran \\ ${ }^{7}$ Endocrinology and Metabolism Research Center, Endocrinology and Metabolism Clinical Sciences Institute, Tehran University of Medical Sciences, Tehran, IR Iran \\ ${ }^{8}$ Diabetes Research Center, Endocrinology and Metabolism Clinical Sciences Institute, Tehran University of Medical Sciences, Tehran, IR Iran \\ "Corresponding author: Cell Therapy and Regenerative Medicine Research Center, Metabolomics and Genomics Research Center, Endocrinology and Metabolism \\ Molecular-Cellular Sciences Institute, Tehran University of Medical Sciences, Tehran, IR Iran, E-mail: barjmand@sina.tums.ac.ir
}

Received 2018 March 10; Revised 2018 May 18; Accepted 2018 July 04.

\begin{abstract}
Background: Among different kinds of cells involved in the wound healing process, fibroblasts play a pivotal role in the proliferation phase of this procedure wherein they induce the production of local growth factors and cytokines. Fetal fibroblasts with low immunogenic property and different wound healing process could be considered as a suitable alternative to neonatal foreskin cell based products in regenerative medicine and cell therapy. Cell therapy is an almost newly introduced method in the medical field and is also a challenging issue, which should assure the safety of the final product and the absence of viral or bacterial contamination with minimal immunogenic response. Therefore, based on current GMP (cGMP) principles, it is a matter of great importance to monitor raw materials' quality and the conformity of all production procedures including cell culture, collection, and cryopreservation with validated standard operating procedures (SOPs). In the current study, we demonstrated the GMP-compatible and clinical-grade fetal fibroblast cells banking to be used for clinical applications.

Methods: All steps of isolation and culturing and cryopreservation of fetal fibroblast cells were performed under the sterile condition according to cGMP guidelines in the clean room. During the cell culture procedures, bacteriological investigation was performed in order to identify the probable contamination of the samples.

Results: Isolated fetal dermal fibroblasts were harvested and stored at early passages. The viability of fibroblasts was $\geq 98 \%$, indicating successful establishment of fibroblast banking. Flow cytometry analysis has revealed the high purity of isolated and cultured fibroblastic population Karyotyping of fibroblasts at the 10th subculture shows a normal diploid male pattern.

Conclusions: The manufactured cells, according to the highest level of safety are considered as the most appropriate treatment option for cellular therapy. Based-on the current evidence, clinical-grade fetal fibroblasts throw new light on efficient and prompt healing of acute and chronic wounds of any etiology.
\end{abstract}

Keywords: Fibroblasts, GMP, Wound healing

\section{Background}

Fibroblasts, as wide spread cells of complex organisms contribute to wound healing of injured tissues with their ability to synthesize collagen resulting in wound edges closure (1-4). Wound healing is an intricate process composed of a set of physiological events that recruits various cell types to fulfill their function in order to close the wound. Fibroblasts play a pivotal role in the proliferation phase of this procedure (4). In adults, remodeling of a wound in damaged organs generally lasts about 2 - 3 weeks and complete normal wound healing process usually needs more time, sometimes years. Despite the fact that deposition of extracellular matrix in the fetal wound healing process is similar to the adult one, the temporal and spatial distribution of fetal extracellular matrix is different from its adult counterpart. Compared to adults, the production and precipitation of extracellular matrix by fetal fibroblasts is much more coordinated with stronger synthetic and secretory phenotype $(5,6)$. Fetal skin repair be- 
fore the third trimester of pregnancy shows minimal inflammation due to the production of particular cytokines, growth factors, faster extracellular matrix deposition, and turnover, which could probably be responsible for scarless fetal wound healing (6-8). Regarding the crucial role of fibroblast in collagen deposition as the key element of skin extracellular matrix, it has been suggested that fetal fibroblasts are the central pillar of wound repair process (9). Some other studies have revealed that different wound healing properties of fetal skin is much more related to the fetal tissue instead of the uterus environment of the fetus, which have raised the intriguing possibility of their application to adult wound healing since 1970 s $(10,11)$. It is not surprising that fetal fibroblasts with low immunogenic property and different wound healing process could be considered as a suitable alternative to neonatal foreskin cell based products in regenerative medicine and cell therapy (12). Cell therapy, as an almost newly introduced method in the medical field, is a challenging issue, which should assure the safety of the final product and the absence of viral or bacterial contamination with minimal immunogenic response $(13,14)$. Good manufacturing practice (GMP), as a quality assurance system, ensures that the quality of final product, focusing on all steps of manufacturing is in accordance with current specifications. Therefore, based on the current GMP (cGMP) principles, it is a matter of great importance to monitor raw materials' quality and the conformity of all production procedures including cell culture, collection, and cryopreservation with validated standard operating procedures (SOPs) (15-17). In this respect, it has been highly recommended to perform cell production in a professionally designed GMP-compliant clean room facility using xeno-free media. Present relevant guidelines focus on progression, production, quality control, and non-clinical and clinical advances in cellular therapy (18). Therefore, when cell preparation complies with GMP regulations, the safety and quality of the final product will be increased (19). To achieve this aim, safe and pure reagents must be used during the entire cell production processes and research-grade reagents must be replaced by valid GMP-grade materials, to extend possible (20). Cell bank establishment is considered as one of the fundamental steps in cell therapy and clinical applications of desired cells (21). In order for GMP-grade cell manufacturing, we designed and established a clean room facility, affiliated to the Cell Therapy and Regenerative Medicine Research Center, to produce the most suitable clinical-grade cells for cell therapy. Based-on our previous studies to establish GMPgrade cell banking, in the current study we demonstrated the GMP-compatible and clinical-grade fetal fibroblast cell banking to be used for clinical applications.

\section{Methods}

Informed consent was obtained from the donor and the fetus was transported to the GMP facility via a tissue container with ice. Fetal skin was harvested from the back of the fetus with a gestational age of less than 12 weeks, which was legally and therapeutically aborted. Following skin harvesting, specimens were immediately immersed in transport medium (DMEM PAA, Austria) / PenicillinStreptomycin and transferred to the clean room facility in less than 6 hours. Harvested tissue was transformed into the culture plate. All steps of isolation and culturing were performed under sterile condition under laminar airflow hood, according to cGMP guidelines in clean room. During the cell culture procedures, bacteriological tests were performed in order to identify the probable contamination of the samples.

\subsection{Tissue Processing and Cell Culture}

Skin sample was gently washed in phosphate-buffered saline (PBS; CliniMACS $®$, MiltenyiBiotec, Germany). The dermal side of the skin was scraped in order to remove its subcutaneous part and then it was sliced into small strips. After that, it was transferred to a $37^{\circ} \mathrm{C}$ water bath and was incubated with $0.5 \%$ (dispase; MP Biomedicals, USA/PBS) for four hours. After incubation, epidermis was removed as a sheet from the skin and dermal sample was washed and gently shaken in PBS. Approximately 10 pieces of sample were placed in a $35-\mathrm{mm}$ tissue culture dish and a cover glass was placed over the tissue pieces. The space between sample pieces under the cover glass was filled with $4^{\circ} \mathrm{C}$ (DMEM-low glucose; PAA, Austria) supplemented with $10 \%$ fetal bovine serum (FBS; Pharma grade, Australian origin and gamma irradiated, PAA, Austria) and also $2 \mathrm{~mL}$ of $4^{\circ} \mathrm{C}$ mentioned medium was added gently to the culture dish. Dishes were placed into the incubator at $37^{\circ} \mathrm{C}, 5 \% \mathrm{CO}_{2}$, and $97 \%$ humidity. Medium renewal was done every 72 hours. When the cells reach approximately $85 \%$ - 90\% confluency, the cover glass was removed and expanded cells were washed twice with $4^{\circ} \mathrm{C}$ PBS and were enzymatically harvested with TrypLE ${ }^{\mathrm{TM}}$ Express (life technologies, USA). Cells were subcultured after evaluating the cell count, purity, and viability using 0.4\% Trypan blue solution (Invitrogen, USA) and hemocytometer. Moreover, chromosomal stability of cultivated fibroblasts was assessed at the10th subculture. In order for long term storage of cultured cells, enzymatically detached fibroblasts were cryopreserved using freezing cold media composed of a final concentration of $10 \%$ dimethylsulfoxide (DMSO; WAK - Chemie Medical GmbH, Germany), 50\% FBS, and 40\% DMEM-low glucose. Cryo vials were placed in a pre-cooled Mr. Frosty freezing 
container and were frozen overnight at $-80^{\circ} \mathrm{C}$. Then, crypreserved cells transfer to liquid nitrogen at $-196^{\circ} \mathrm{C}$. All banked cryovials were labelled carefully and their data was documented correctly.

Approximately $5 \times 10^{5}$ subcultured fibroblasts were resuspended in FACS-buffer (3\% BSA in PBS) in order to analyze the specific cell surface markers using flow cytometry. Following that, cell suspension was incubated with desired Fluorescein Isothiocyanate (FITC) - conjugated antibodies, CD146, CD106, CD45, and CD29 for 60 minutes at $4^{\circ} \mathrm{C}$ and fibroblasts were analyzed on a fluorescence-activated cell sorter (FACS; Partec, Denmark).

\section{Results}

Isolated fetal dermal fibroblasts were harvested and stored at early passages. The viability of fibroblasts was $\geq 98 \%$ indicating successful establishment of fibroblast banking. Spindle-shaped morphological features of dermal fibroblasts are shown in Figure 1. Karyotyping of fibroblasts at the 10th subculture shows a normal diploid male pattern (Figure 2).

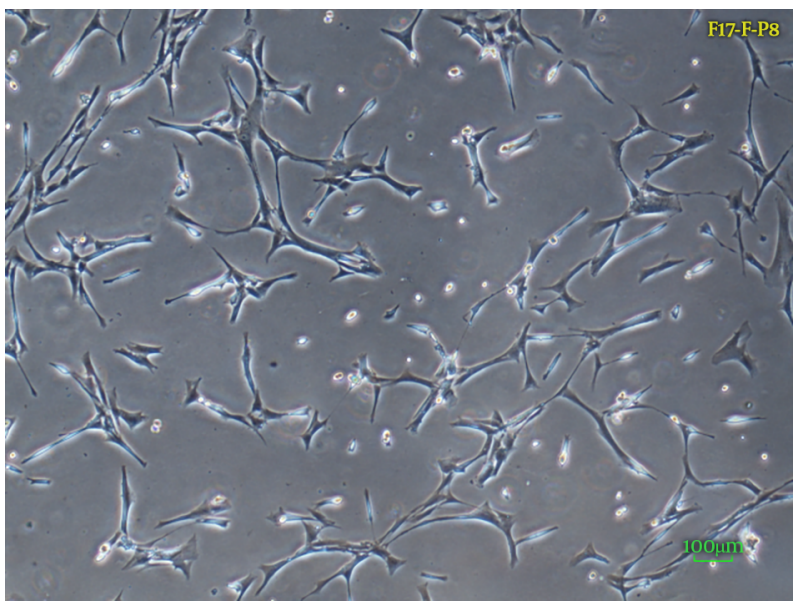

Figure 1. 40X Inverted light microscopy of fetal dermal fibroblasts morphology

Screening CD markers have demonstrated the presence of CD106 and CD29 and the absence of CD146 and CD45 molecules on the fibroblasts surface (Figure 3). Therefore, according to flow cytometric data analysis, the lack of CD146 expression, which is positive in mesenchymal cells, has revealed the high purity of isolated and cultured fibroblastic population.

\section{Discussion}

Fibroblasts, as the key player of connective tissue, have a crucial role in the structural integrity of the tissue by secreting extracellular proteins such as proteinases leading to regulate the structure of the whole tissue. Dermal fibroblasts existing in the skin are considered as an important component of wound healing process and could be isolated and purified from skin specimens (22). These cells are similar to mesenchymal stem cells (MSCs) phenotypically. Therefore, the discrimination between these two types of cells is crucially important. However, there are no specific markers to discriminate between MSCs and fibroblasts. As CD146 is expressed only in MSCs, it could help scientists identify MSCS. On the other hand, CD106 is positive in both cells while they are expressed in MSCs around 10fold higher than in fibroblasts. Additionally, CD146 are express just in MSCs (23). The most commonly used dermal derivatives appropriate for clinical applications are developed from foreskin tissues obtained from young donors. On the other hand, using fetal dermal fibroblast based products demonstrated that complete healing process of burns and wounds does not need further surgery or grafting methods. Thus, fetal skin is introduced as a prompt and effective treatment solution for wound healing regardless of the etiology of the wound (24). This aroused great interest in using fetal skin cells instead of isolated cells from conventional neonatal or young foreskin. Some studies have revealed that the use of fetal dermal cell derivatives for pediatric burn patients have led to a rapid and complete wound closure with the lack of retraction and a little hypertrophy of new skin in all subjects involved in the study $(25,26)$. Scientists have shown that using fetal skin cells on an incurable ulcer (has remained unhealed for 14 years) led to its efficient and also scarless healing. Surprisingly, Hirt-Burri et al., reported promising results indicating that the etiology of the wound is not a determinant of wound healing efficacy of fetal skin cells (21). The fact that fetal skin wound healing does not leave scars is due to more rapid re-epithelialization, no inflammation, and normal tissue recovery architecture (1). Since Shiraha et al., reported that skin fibroblast's growth and migratory properties decrease with age $(27,28)$. Elucidation of unique fetal fibroblasts properties involved in wound healing process turned the spotlight on their potential therapeutic application for acute and chronic wound repair and regeneration. Obviously, some major obstacles to clinical trials of fetal skin derivatives could be problems with taking legal steps to contract the fetus donation, harvesting and culturing desired cells, as well as clinical-grade fetal cell banking (12). Although fetal cell banking has been used for medical purposes for many years, the GMP-grade and 

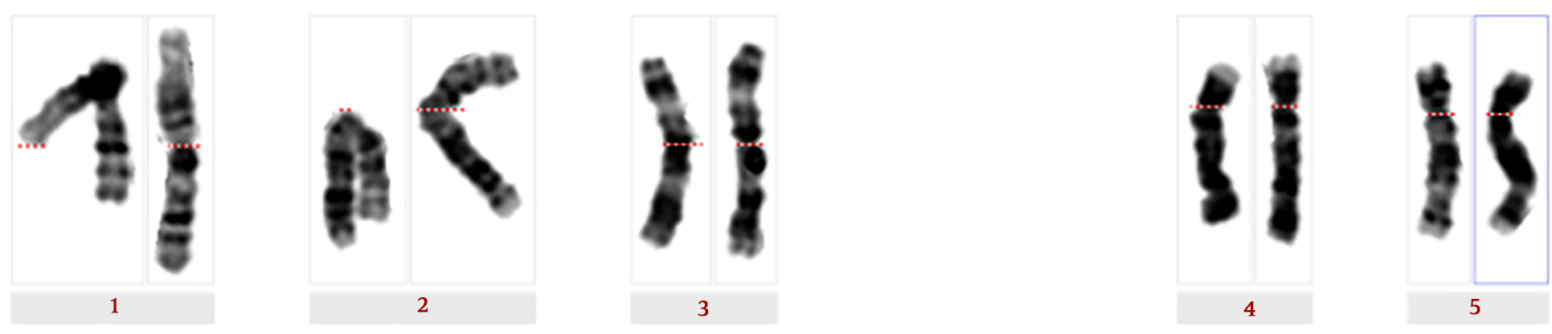

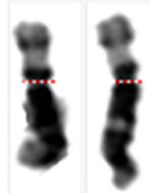

6

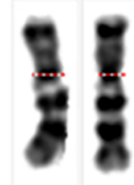

7

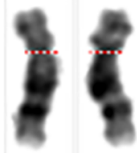

8
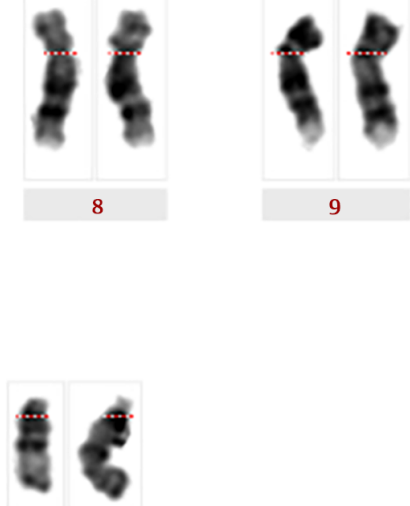

15

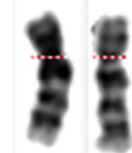

10

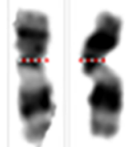

11

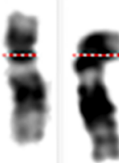

12

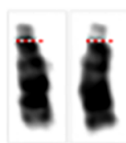

13

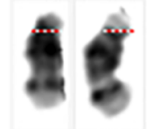

14

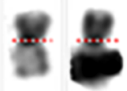

20
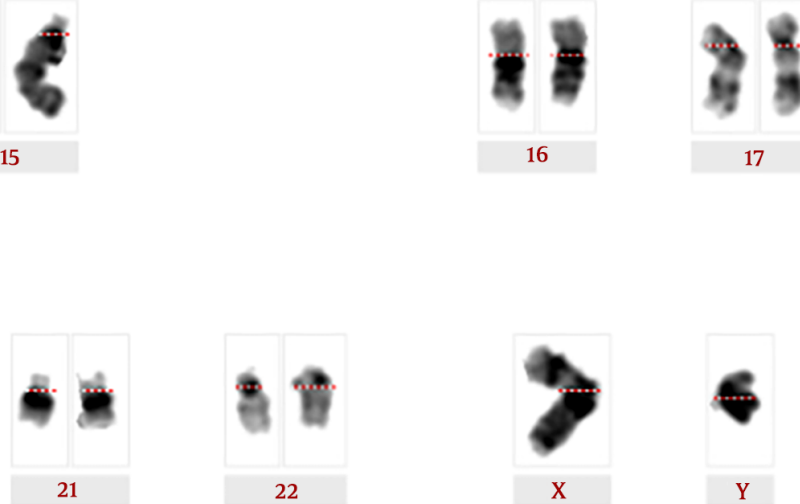

17

18

Figure 2. Karyotype characterization of in vitro derived fetal fibroblasts at 10th subculture

xeno-free cell banking is a new perspective on this field leading to supply much safer cell based products in case of compatibility with human health. Prathalingam et al., reported the production of GMP-grade human fibroblast line, NcliFed1A, as a validated resource of feeder cell line for human embryonic stem cells (hESCs) and iPSCs in clinical community (29). Regarding mesenchymal stem cell harvesting, it has been demonstrated that common enzymatic cell isolation procedure may led to protein degradation while explant culture method, as a less invasive alternative, resulted in reduced probability of cellular damage and increased cellular viability (30). Enzymatic digestion with consequent mechanical damage during centrifuga- tion times seems as a laborious procedure that may lead to reduced cell viability (31). It has been indicated that the characteristics of isolated cells may be altered by the use of enzymatic digestion method as a repercussion of different environment of the cells (32). In explant culture method, the processing time for the tissue is faster than conventional enzymatic method. Moreover, it has been shown that the less use of enzymes in cell isolation procedure, the more elimination of xeno- or bacterial-derived agents. This makes the final products safer and more suitable for further clinical applications (31). Due to this fact, in this study explant culture method was performed to reduce the potential destroying effect caused by enzymatic 

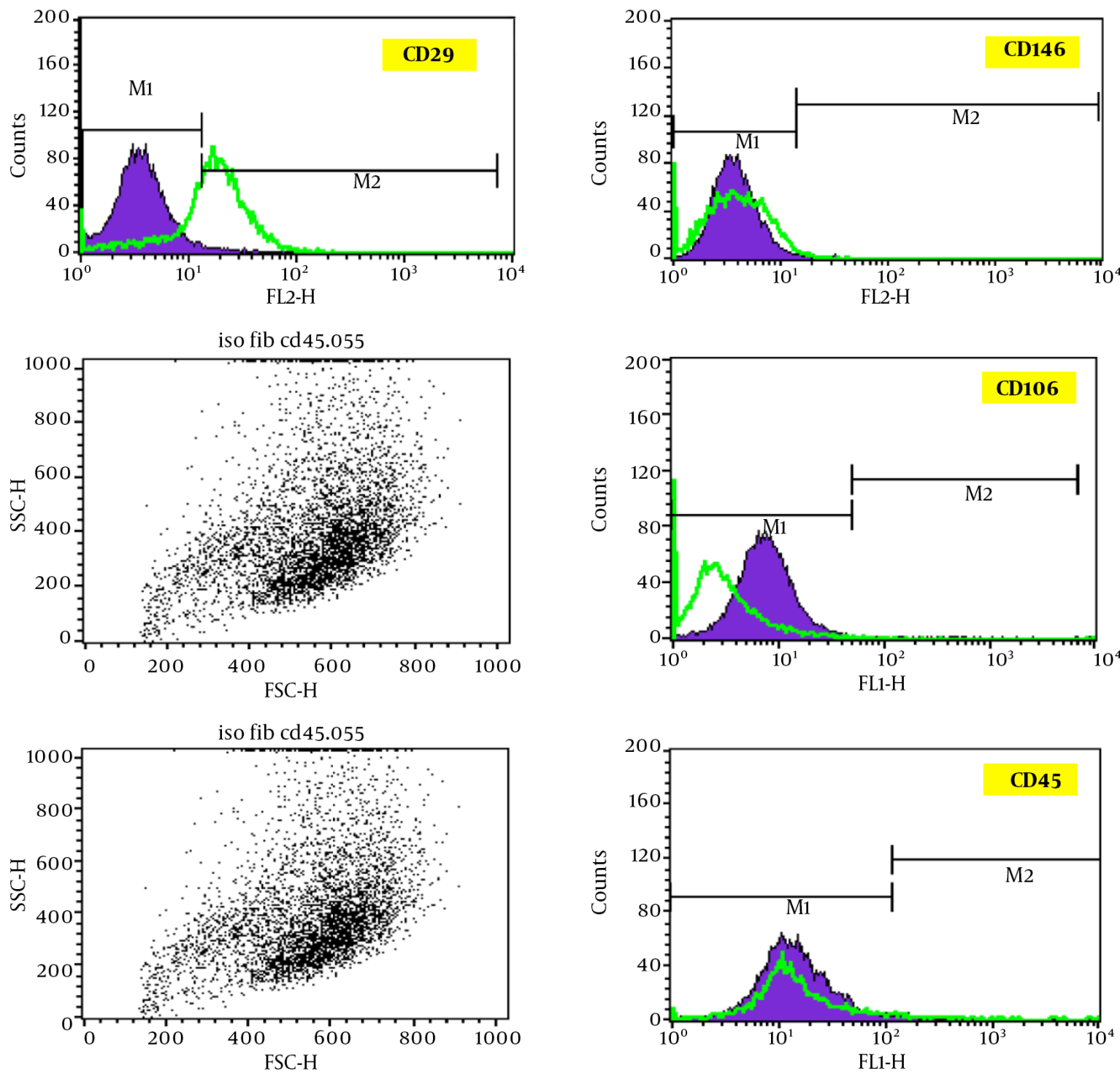

Figure 3. Characterization of dermal fibroblasts cell surface markers using flow cytometric analysis for CD146, CD45, CD106, and CD29

method. The majority of human embryonic stem cell lines used in clinical trials are not cultivated and isolated according to GMP standards all over the world. In order for clinical application of manufactured cells, their establishment needs strict clean room conditions, exclusive use of GMP compatible materials, and careful documentation of all required data $(33,34)$. Thus, all steps of cell manufacturing process must be implemented in accordance with necessities of GMP, if possible. When there is no alternative to research-grade reagents, the animal origin could be used if the manufacturer officially confirms their compliance with GMP regulations. We previously reported the clinicalgrade cultivation and banking of human Schwann cells, human fetal liver-derived mesenchymal stem cells, and human adipose tissue-derived mesenchymal stem cells (19, $35,36)$. In the current study, in order for clinical-grade fibroblasts establishment, according to the Stringent Ethical guidelines, informed consent was obtained from the donor. In the next step, all procedures of cell cultivation and banking were performed under sterile condition in clean rooms using GMP-compatible raw materials as far as possible. Moreover, to assure that the final product will 
meet safety standards, the karyotype and sterility of GMPgrade fetal fibroblasts were investigated. To avoid further transmission of xenogenic, infectious reagents, and transmissible spongiform encephalopathy (TSE) existing in fetal bovine serum (FBS), according to European medicines agency (EMEA) recommendations the use of FBS must be prohibited $(37,38)$. This special kind of FBS is compatible with the current guidelines of biopharmaceutical products. Based on these safety measures, we have chosen it as an appropriate alternative to conventional FBS. TrypLE Select (life technologies, USA) was another substitute for animal origin enzymes, as a xeno-free and very gentle detachment enzyme (39). In summary, in this investigation we establish GMP-compliant human fetal skin fibroblast banking as a potent candidate to further clinical applications for acute and chronic wounds healing. To this end, all production procedures were performed in clean rooms in accordance with GMP guidelines and standards. The use of GMP certified raw materials ensure the high quality and efficacy of final product for therapeutic purposes. Harvested fetal fibroblasts were labeled and stored in liquid nitrogen at $-196^{\circ} \mathrm{C}$.

\subsection{Conclusion}

Preparing cell based products for clinical applications needs optima quality and safety adhering to GMP guidelines, which are represented by both European medicines agency and the food and drug administration. To achieve this goal, all parameters involved in the manufacturing process must be strictly controlled to assure the compatibility of the final product with current GMP regulations. The manufactured cells, according to the highest level of safety, are considered as the most appropriate treatment option for cellular therapy. Based on the current evidence, clinical-grade fetal fibroblasts throw new light on efficient and prompt healing of acute and chronic wounds of any etiology. While it is true that this valuable source of fibroblast is possibly an ideal candidate for scarless healing of wounds, further studies are required to clarify the exact mechanism and potential risk treatments of this new therapy.

\section{Acknowledgments}

The authors would like to thank Dr. Majid Maanavi and Dr. Mohsen Khorshidi for their assistance in this project.

\section{References}

1. Ho S, Marcal H, Foster LJ. Towards scarless wound healing: a comparison of protein expression between human, adult and foetal fi- broblasts. Biomed Res Int. 2014;2014:676493. doi: 10.1155/2014/676493. [PubMed: 24605334]. [PubMed Central: PMC3925539].

2. Parekh A, Hebda PA. The Contractile Phenotype of Dermal Fetal Fibroblasts in Scarless Wound Healing. Curr Pathobiol Rep. 2017;5(3):2717. doi: 10.1007/s40139-017-0149-3. [PubMed: 29038745]. [PubMed Central: PMC5640269].

3. Ghetti M, Topouzi H, Theocharidis G, Papa V, Williams G, Bondioli E, et al. Subpopulations of dermal skin fibroblasts secrete distinct extracellular matrix: implications for using skin substitutes in the clinic. Br J Dermatol. 2017. doi: 10.1111/bjd.16255. [PubMed: 29266210].

4. Zhang Q, Wei F, Fong CC, Yu WK, Chen Y, Koon CM, et al. Transcriptional profiling of human skin fibroblast cell line Hs27 induced by herbal formula Astragali Radix and Rehmanniae Radix. J Ethnopharmacol. 2011;138(3):668-75. doi: 10.1016/j.jep.2011.08.080. [PubMed: 22075453]

5. Yates CC, Hebda P, Wells A. Skin wound healing and scarring: fetal wounds and regenerative restitution. Birth Defects Res C Embryo Today. 2012;96(4):325-33. doi: 10.1002/bdrc.21024. [PubMed: 24203921]. [PubMed Central: PMC3967791].

6. Li M, Zhao Y, Hao H, Han W, Fu X. Theoretical and practical aspects of using fetal fibroblasts for skin regeneration. Ageing Res Rev. 2017;36:32-41. doi: 10.1016/j.arr.2017.02.005. [PubMed: 28238941].

7. Walraven M, Akershoek JJ, Beelen RH, Ulrich MM. In vitro cultured fetal fibroblasts have myofibroblast-associated characteristics and produce a fibrotic-like environment upon stimulation with TGF-beta1: Is there a thin line between fetal scarless healing and fibrosis? Arch Dermatol Res. 2017;309(2):111-21. doi: 10.1007/s00403-016-1710-3. [PubMed: 28004279].

8. Hotchin NA, Zuliani T, Saiagh S, Knol AC, Esbelin J, Dreno B. Fetal Fibroblasts and Keratinocytes with Immunosuppressive Properties for Allogeneic Cell-Based Wound Therapy. PLOS ONE. 2013;8(7). e70408. doi: 10.1371/journal.pone.0070408.

9. Lorenz HP, Whitby DJ, Longaker MT, Adzick NS. Fetal wound healing. The ontogeny of scar formation in the non-human primate. Ann Surg. 1993;217(4):391-6. [PubMed: 8466310]. [PubMed Central: PMC1242806].

10. Lorenz HP, Longaker MT, Perkocha LA, Jennings RW, Harrison MR, Adzick NS. Scarless wound repair: a human fetal skin model. Development. 1992;114(1):253-9. [PubMed: 1576963].

11. Longaker MT, Whitby DJ, Ferguson MW, Lorenz HP, Harrison MR, Adzick NS. Adult skin wounds in the fetal environment heal with scar formation. Ann Surg. 1994;219(1):65-72. [PubMed: 8297179]. [PubMed Central: PMC1243092].

12. Rolfe KJ, Cambrey AD, Richardson J, Irvine LM, Grobbelaar AO, Linge C. Dermal fibroblasts derived from fetal and postnatal humans exhibit distinct responses to insulin like growth factors. BMC Dev Biol. 2007;7:124. doi: 10.1186/1471-213X-7-124. [PubMed: 17988375]. [PubMed Central: PMC2211318].

13. Mizuno N, Shiba H, Ozeki Y, Mouri Y, Niitani M, Inui T, et al. Human autologous serum obtained using a completely closed bag system as a substitute for foetal calf serum in human mesenchymal stem cell cultures. Cell Biol Int. 2006;30(6):521-4. doi: 10.1016/j.cellbi.2006.01.010. [PubMed: 16616867].

14. Pytlik R, Stehlik D, Soukup T, Kalbacova M, Rypacek F, Trc T, et al. The cultivation of human multipotent mesenchymal stromal cells in clinical grade medium for bone tissue engineering. Biomaterials. 2009;30(20):3415-27. doi: 10.1016/j.biomaterials.2009.03.001. [PubMed: 19362364].

15. Unger C, Skottman H, Blomberg P, Dilber MS, Hovatta O. Good manufacturing practice and clinical-grade human embryonic stem cell lines. Hum Mol Genet. 2008;17(R1):R48-53. doi: 10.1093/hmg/ddn079. [PubMed: 18632697].

16. Thirumala S, Goebel WS, Woods EJ. Clinical grade adult stem cell banking. Organogenesis. 2009;5(3):143-54. [PubMed: 20046678]. [PubMed Central: PMC2781095]. 
17. Arjmand B, Goodarzi P, Falahzadeh K, Aghayan HR, Rahim F, Mohamadi-Jahani F, et al. GMP-Compliant Perinatal Tissue-Derived Stem Cells. In: Arjmand B, editor. Perinatal Tissue-Derived Stem Cells: Alternative Sources of Fetal Stem Cells. Switzerland: Springer; 2016. p. 189-213. doi:10.1007/978-3-319-46410-7_9.

18. Aghayan HR, Arjmand B, Burger SR. GMP Facilities for Clinical Cell Therapy Product Manufacturing: A Brief Review of Requirements and Design Considerations. In: Arjmand B, editor. Perinatal Tissue-Derived Stem Cells: Alternative Sources of Fetal Stem Cells. Switzerland: Springer; 2016. p. 215-27.

19. Aghayan HR, Arjmand B, Norouzi-Javidan A, Saberi H, Soleimani M, Tavakoli SA, et al. Clinical grade cultivation of human Schwann cell, by the using of human autologous serum instead of fetal bovine serum and without growth factors. Cell Tissue Bank. 2012;13(2):281-5. doi: 10.1007/s10561-011-9250-8. [PubMed: 21484231].

20. Bieback K, Kinzebach S, Karagianni M. Translating research into clinical scale manufacturing of mesenchymal stromal cells. Stem cells international. 2010;2010.

21. Hirt-Burri N, Ramelet AA, Raffoul W, de Buys Roessingh A, Scaletta C, Pioletti D, et al. Biologicals and fetal cell therapy for wound and scar management. ISRN Dermatol. 2011;2011:549870. doi: 10.5402/2011/549870. [PubMed: 22363853]. [PubMed Central: PMC3262533].

22. Takashima A. Establishment of fibroblast cultures. Curr protocol cell biol.1998;(1):2.1.1-2.1.12.

23. Halfon S, Abramov N, Grinblat B, Ginis I. Markers distinguishing mesenchymal stem cells from fibroblasts are downregulated with passaging. Stem Cells Dev. 2011;20(1):53-66. doi: 10.1089/scd.2010.0040. [PubMed: 20528146].

24. Applegate LA, Scaletta C, Hirt-Burri N, Raffoul W, Pioletti D. Whole-cell bioprocessing of human fetal cells for tissue engineering of skin. Skin Pharmacol Physiol. 2009;22(2):63-73. doi: 10.1159/000178865. [PubMed: 19188754]

25. De Buys Roessingh AS, Hohlfeld J, Scaletta C, Hirt-Burri N, Gerber S, Hohlfeld P, et al. Development, Characterization, and Use of a Fetal Skin Cell Bank for Tissue Engineering in Wound Healing. Cell Transplant. 2017;15(8-9):823-34. doi:10.3727/000000006783981459.

26. Hohlfeld J, de Buys Roessingh A, Hirt-Burri N, Chaubert P, Gerber S, Scaletta C, et al. Tissue engineered fetal skin constructs for paediatric burns. Lancet. 2005;366(9488):840-2. doi: 10.1016/s01406736(05)67107-3.

27. Nodder S, Martin P. Wound healing in embryos: a review. Anat Embryol (Berl). 1997;195(3):215-28. [PubMed: 9084820].

28. Shiraha H, Gupta K, Drabik K, Wells A. Aging fibroblasts present reduced epidermal growth factor (EGF) responsiveness due to preferential loss of EGF receptors. J Biol Chem. 2000;275(25):19343-51. doi: 10.1074/jbc.M000008200. [PubMed: 10764734].
29. Prathalingam N, Ferguson L, Young L, Lietz G, Oldershaw R, Healy $\mathrm{L}$, et al. Production and validation of a good manufacturing practice grade human fibroblast line for supporting human embryonic stem cell derivation and culture. Stem Cell Res Ther. 2012;3(2):12. doi: 10.1186/scrt103. [PubMed: 22472092]. [PubMed Central: PMC3392772].

30. Yoon JH, Roh EY, Shin S, Jung NH, Song EY, Chang JY, et al. Comparison of explant-derived and enzymatic digestion-derived MSCs and the growth factors from Wharton's jelly. Biomed Res Int. 2013;2013:428726. doi: 10.1155/2013/428726. [PubMed: 23653895]. [PubMed Central: РMC3638666].

31. Priya N, Sarcar S, Majumdar AS, SundarRaj S. Explant culture: a simple, reproducible, efficient and economic technique for isolation of mesenchymal stromal cells from human adipose tissue and lipoaspirate. J Tissue Eng Regen Med. 2014;8(9):706-16. doi: 10.1002/term.1569. [PubMed: 22837175].

32. Gittel C, Brehm W, Burk J, Juelke H, Staszyk C, Ribitsch I. Isolation of equine multipotent mesenchymal stromal cells by enzymatic tissue digestion or explant technique: comparison of cellular properties. BMC Vet Res. 2013;9:221. doi: 10.1186/1746-6148-9-221. [PubMed: 24168625]. [PubMed Central: PMC4228449].

33. Tannenbaum SE, Turetsky TT, Singer O, Aizenman E, Kirshberg S, Ilouz N, et al. Derivation of xeno-free and GMP-grade human embryonic stem cells-platforms for future clinical applications. PLoS One. 2012;7(6). e35325. doi: 10.1371/journal.pone.0035325. [PubMed: 22745653]. [PubMed Central: PMC3380026].

34. Burger SR. Current regulatory issues in cell and tissue therapy. Cytotherapy. 2003;5(4):289-98. doi: 10.1080/14653240310002324. [PubMed: 12944234].

35. Larijani B, Aghayan HR, Goodarzi P, Arjmand B. GMP-grade human fetal liver-derived mesenchymal stem cells for clinical transplantation. Methods Mol Biol. 2015;1283:123-36. doi: 10.1007/7651_2014_101. [PubMed: 25092054].

36. Aghayan HR, Goodarzi P, Arjmand B. GMP-compliant human adipose tissue-derived mesenchymal stem cells for cellular therapy. In: Turksen K, editor. Stem Cells and Good Manufacturing Practices. Springer; 2014. p. 93-107.

37. Brooke G, Rossetti T, Pelekanos R, Ilic N, Murray P, Hancock S, et al. Manufacturing of human placenta-derived mesenchymal stem cells for clinical trials. Br J Haematol. 2009;144(4):571-9. doi: 10.1111/j.13652141.2008.07492.x. [PubMed: 19077161].

38. Bieback K, Schallmoser K, Kluter H, Strunk D. Clinical Protocols for the Isolation and Expansion of Mesenchymal Stromal Cells. Transfus Med Hemother. 2008;35(4):286-94. doi: 10.1159/000141567. [PubMed: 21512644]. [PubMed Central: PMC3076361].

39. Arjmand B, Aghayan HR. Cell manufacturing for clinical applications. Stem Cells. 2014;32(9):2557-8. doi: 10.1002/stem.1751. [PubMed: 24891087]. 